\title{
Update on pediatric dystonias: etiology, epidemiology, and management
}

\author{
This article was published in the following Dove Press journal: \\ Degenerative Neurological and Neuromuscular Disease \\ II April 2012 \\ Number of times this article has been viewed
}

\section{Emilio Fernández-Alvarez' Nardo Nardocci ${ }^{2}$ \\ 'Neuropediatric Department, Hospital San Juan de Dios, Barcelona, Spain; ${ }^{2}$ Child Neurology Department, Fondazione IRCCS Istituto Neurologico "C. Besta”, Milano, Italy}

\begin{abstract}
Dystonia is a movement disorder characterized by sustained muscle contractions producing twisting, repetitive, and patterned movements or abnormal postures. Dystonia is among the most commonly observed movement disorders in clinical practice both in adults and children. It is classified on the basis of etiology, age at onset of symptoms, and distribution of affected body regions.

Etiology: The etiology of pediatric dystonia is quite heterogeneous. There are many different genetic syndromes and several causes of symptomatic syndromes. Dystonia can be secondary to virtually any pathological process that affects the motor system, and particularly the basal ganglia.

Classification: The etiological classification distinguishes primary dystonia with no identifiable exogenous cause or evidence of neurodegeneration and secondary syndromes.

Treatment: Treatment for most forms of dystonia is symptomatic and includes drugs (systemic or focal treatments, such as botulinum toxin) and surgical procedures. There are several medications including anticholinergic, dopamine-blocking and depleting agents, baclofen, and benzodiazepines. In patients with dopamine synthesis defects L-dopa treatment may be very useful. Botulinum toxin treatment may be helpful in controlling the most disabling symptoms of segmental or focal dystonia. Long-term electrical stimulation of the globus pallidum internum appears to be especially successful in children suffering from generalized dystonia.
\end{abstract}

Keywords: movement disorders, pediatric dystonia, primary dystonias, secondary dystonias

\section{Introduction}

Dystonia is a movement disorder characterized by sustained muscle contractions producing twisting, repetitive, and patterned movements or abnormal postures. Dystonia has a wide clinical spectrum ranging from minimal or benign self-limiting features to severe cases. ${ }^{1-3}$ Dystonia is classified on the basis of: (i) etiology, (ii) age at onset of symptoms, and (iii) distribution of affected body regions. The etiology of pediatric dystonia is heterogeneous (Table 1). ${ }^{4}$ The etiological classification distinguishes primary dystonia with no identifiable exogenous cause or evidence of neurodegeneration and secondary syndromes. Primary diseases may be divided in pure, plus, and paroxysmal. In primary pure forms, dystonia is the only sign of the disease (with the exception of tremor), and the cause is either genetic or unknown. Primary plus syndromes are characterized by dystonia associated with an additional movement disorder (eg, myoclonus or parkinsonism). Finally, primary paroxysmal syndromes include conditions characterized by abnormal movements including dystonia occurring in brief episodes with normality in between. Secondary dystonic forms
Correspondence: Emilio Fernández-Alvarez Neuropediatric Department, Hospital San Juan de Dios, Avda Sant Joan de Déu s/n 08950 Barcelona, Spain

Tel +34 629719479

Email efernandez@hsjdbcn.org 
Table I Classification of dystonias by etiology

\begin{tabular}{|c|c|}
\hline \multicolumn{2}{|l|}{ Primary } \\
\hline - Primary pure & $\begin{array}{l}\text { Dystonia is the only clinical sign } \\
\text { (apart from tremor), and there is no } \\
\text { identifiable exogenous cause or other } \\
\text { inherited or degenerative disease }\end{array}$ \\
\hline - Primary plus & $\begin{array}{l}\text { Dystonia is a prominent sign but is associated } \\
\text { with another movement disorder, } \\
\text { for example myoclonus or parkinsonism. } \\
\text { There is no evidence of neurodegeneration }\end{array}$ \\
\hline - Primary paroxysmal & $\begin{array}{l}\text { Dystonia occurs in brief episodes with } \\
\text { normalcy in between. These disorders } \\
\text { are classified as idiopathic (often familial } \\
\text { although sporadic cases also occur) } \\
\text { and symptomatic because of a variety } \\
\text { of causes }\end{array}$ \\
\hline Secondary & $\begin{array}{l}\text { Dystonia is a symptom of an identified } \\
\text { neurological condition, such as a focal brain } \\
\text { lesion, exposure to drugs or chemicals }\end{array}$ \\
\hline Heredodegenerative & $\begin{array}{l}\text { Dystonia is a feature, amongst other } \\
\text { neurological signs, of a heredodegenerative or } \\
\text { metabolic disorder }\end{array}$ \\
\hline
\end{tabular}

include syndromes, where dystonia is a prominent sign of a heredodegenerative condition, or where dystonia is due to exogenous factors (eg, perinatal injury, medications, brain tumor, infections).

A second axis of the classification distinguishes pediatric onset ( $<18$ years) from adult-onset ( $>19$ years) cases (Table 2). Finally, the third axis based on the somatic distribution of dystonia distinguishes focal, segmental, multifocal, generalized, and unilateral (hemidystonia) forms (Table 3).

Dystonic syndromes are among the most commonly observed movement disorders in clinical practice both in adults and children, with a prevalence ranging between 2 and 50 cases per million for early-onset dystonia ( $<26$ years) and between 30 and 7320 cases per million for late-onset dystonia ( $>26$ years)..$^{5-7}$

In this review we will focus on dystonia that affects children arbitrarily limited to individuals younger than 18 years of age. We will discuss the primary dystonias with pediatric onset divided in 'pure' dystonias (DYT1, DYT6, DYT13, DYT17), 'dystonias-plus' associated to myoclonus (DYT11

Table 2 Classification of dystonias by age at onset

\begin{tabular}{ll}
\hline Early onset & Usually starting in a limb and frequently \\
(variably defined & spreading to involve other limbs and \\
as 20-30 years) & the trunk \\
Late onset & Usually starting in the neck (including the \\
& larynx), the cranial muscles or one arm. \\
& Tends to remain localized with restricted \\
& progression to adjacent muscles \\
\hline
\end{tabular}

and DYT15), and 'dystonias-plus' associated with parkinsonism (DYT5, DYT12, DYT16). Finally, we will include the most frequent secondary dystonias.

\section{Primary pure dystonia syndromes}

In the pure form, dystonia is the only clinical sign (apart from tremor). Pediatric primary pure dystonia is a rare condition; it includes familial and sporadic cases. Seven loci have been mapped for primary dystonia starting in children, including DYT1, DYT4, DYT6, DYT13, and DYT17 (Table 4). Among them, at this moment only two causative genes are known, DYT1/TOR1A and DYT6/THAP1. ${ }^{8}$

\section{DYTI (TORIA): Early-onset dystonia}

Early-onset dystonia caused by the DYT1 mutation represents the most common and most severe form of primary dystonia. It accounts for $16 \%-53 \%$ of pediatric onset dystonia (POD) in non-Jewish populations and $80 \%-90 \%$ of patients in the Ashkenazi Jewish population. ${ }^{9-11}$

The disease frequency in the Ashkenazi Jewish population was calculated to be 1:3000-1:9000. In the non-Jewish population, the frequency is approximately five times lower. ${ }^{12,13}$

Typically, DYT1 dystonia starts in childhood or adolescence. The initial symptom is usually a focal action dystonia involving one limb (writing dystonia, walking dystonia with foot inversion or eversion). Dystonia subsequently spreads to involve other body regions, becomes less-action specific, and may also be present at rest. Patients presenting with leg dystonia at onset have usually an earlier onset (average age 9 years) and a generalized dystonia after a few months or years. Patients presenting with arm dystonia have a later onset (average age, 15 years), and generalization of dystonia is less frequent. Dystonia may also start in the neck or in the cranial muscles. ${ }^{14}$

Overall, up to $65 \%$ of patients with DYT1 dystonia have a generalized dystonia, with the limbs the most frequent sites involved. Cranial muscles are less commonly involved, showing in approximately $11 \%-18 \%$ of patients. Affected family members may have an adult onset and more frequently

Table 3 Classification of dystonias by distribution

\begin{tabular}{ll}
\hline Focal & Single body region \\
Segmental & Contiguous body regions \\
Multifocal & Noncontiguous body regions \\
Generalized & Both legs and at least one other body \\
& part \\
Hemidistonia & Half of the body \\
\hline
\end{tabular}


Table 4 Molecular classification of nonparoxysmal dystonias starting in children

\begin{tabular}{|c|c|c|c|c|}
\hline Gene & Locus & Designation & Gene product & Type \\
\hline \multicolumn{5}{|c|}{ With autosomal dominant inheritance } \\
\hline DYTI & $9 q 34$ & Idiopathic torsion dystonia (ITD) & Torsin A (TOR/A) & Primary pure \\
\hline DYT4 & Unknown & Idiopathic torsion dystonia/whispering dysphonia & Unknown & Primary pure \\
\hline DYT5 & $14 q 22.1$ & Deficit GTPCH & GTP-cyclohydrolase I (GCHI) & Primary plus \\
\hline DYT6 & $8 p|I-2|$ & Adolescent/early adult-onset & N-terminal THAP domain (THAPI) & Primary pure \\
\hline DYTII & $7 q 21 \mathrm{AD}$ & Myoclonic dystonia & $\varepsilon$-sarcoglycan (SGCE) & Primary plus \\
\hline DYTI2 & $9 q 13 A D$ & Rapid-onset dystonia parkinsonism & $\mathrm{Na}^{+} / \mathrm{K}^{+}$-ATPase $($ATPIA3) & Primary plus \\
\hline DYTI3 & Ip36.13-36.32 & $\begin{array}{l}\text { Early-onset dystonia with cranial cervical } \\
\text { and upper limb involvement }\end{array}$ & Unknown & Primary pure \\
\hline DYTI5 & $|8 p| 1$ & Alcohol-responsive myoclonic dystonia & Unknown & Primary plus \\
\hline \multicolumn{5}{|c|}{ With autosomal recessive inheritance } \\
\hline DYTI6 & $2 q 31.2$ & Young onset dystonia-parkinsonism & Kinase PKR (PRKRA) & Primary plus \\
\hline DYTI7 & $20 p|1.22-q| 3.12$ & Autosomal recessive primary focal TD & Unknown & Primary pure \\
\hline \multicolumn{5}{|c|}{ With X-linked inheritance } \\
\hline DYT3 & $X q 13.1$ & X-linked dystonia/parkinsonism & $\begin{array}{l}\text { TATA-binding-protein-associated } \\
\text { factor I }(T A F I)\end{array}$ & Primary plus \\
\hline & $\mathrm{Xql} 3$ & $\begin{array}{l}\text { X-linked dystonia-deafness syndrome } \\
\text { (Mohr-Tranebjaerg syndrome) }\end{array}$ & $\begin{array}{l}\text { Mitocondrial import inner membrane } \\
\text { translocase Tim8A (TIMM8A) }\end{array}$ & \\
\hline
\end{tabular}

with neck involvement. Unusual phenotypes such as isolated blepharospasm and unilateral myoclonic dystonia have been reported. ${ }^{15}$

Some patients with $D Y T 1$ dystonia may present a dramatic worsening of dystonia called "status dystonicus" during the course of the disease. ${ }^{16}$ The DYT1 gene product, TorsinA, is a member of the AAA1 superfamily of ATPases associated with a variety of cellular activities. It performs critical functions related to protein degradation, membrane trafficking, vesicle fusion and organelle movement, cytoskeletal dynamics, and correct folding of proteins. ${ }^{17}$

Torsin A is almost ubiquitously expressed and its expression in the brain is restricted to neurons, where it is associated with the endoplasmic reticulum (ER). In cellular models expressing the pathogenic GAG deletion, mutant TorsinA is redistributed from the ER lumen to the nuclear envelope (NE). ${ }^{18}$ These cells also display abnormal morphology and thickening of the NE, including generation of whorled membrane inclusions that appear to derive from the ER and NE. These inclusions are associated with the vesicular monoamine transporter VMAT2, a finding that might functionally relate Torsin A to the dopaminergic system. ${ }^{19}$ In addition, TorsinA has been found to regulate cellular trafficking of the dopamine transporter and other membrane-bound proteins. It has also been shown that the mutant TorsinA interferes with cytoskeletal events that may affect the development of neuronal pathways in the brain, and that it is prematurely degraded by both the proteasome and macroautophagy pathways. ${ }^{20}$ Recently it has been shown that TorsinA controls the stability of synaptic vesicle proteins and affects synaptic vesicle turnover in neurons. ${ }^{21}$

\section{Non-DYTI early-onset primary dystonias}

A large group of POD patients is not due to the DYT1 mutation. DYT6 dystonia was described in two families of GermanMennonite origin. ${ }^{22}$ The phenotype is defined as mixed because it is different from the typical pediatric onset: variable age at onset ranging from infancy to adulthood (range, 5-38 years; mean, 18.6 years), marked involvement of cranial and cervical muscles, and generalization of dystonia occurs in about half of the patients. ${ }^{23}$ The DYT6 gene product, Thanatos-associated protein 1 (THAP1), is a member of a family of cellular factors sharing a highly conserved DNAbinding THAP1 domain, which is an atypical zinc finger, and can regulate endothelial cell proliferation. ${ }^{24} \mathrm{~A}$ proposed disease mechanism is that DYT6 mutations may disrupt THAP1 binding to DNA and produce transcriptional dysregulation. It has been recently demonstrated that a physical interaction occurs between THAP1 and the TOR1A promoter, which is abolished by pathogenic mutations. ${ }^{25}$

This link is probably not just a simple THAP1-Tor1A promoter interaction, but is likely to involve other genes as well. Interestingly, THAP1 also binds to the promoter region of a TAF1 transcript that is implicated in a primary plus dystonia form (adult-onset X-linked dystonia parkinsonism). ${ }^{26}$

Another rare early onset cause of primary dystonia is DYT13 mutation, which was identified in a large Italian family. ${ }^{27}$ The prevalent phenotype is a pediatric-onset 
upper-body dystonia with a frequent involvement of the cranial cervical region and a relatively benign course.

DYT17 primary dystonia has been reported as an example of autosomal recessive POD. ${ }^{28,29}$ The locus for DYT17 has been assigned to chromosome 20 .

\section{Primary plus syndromes}

Dystonia is the prominent sign in dystonia plus syndromes, but it is associated with other movement disorders (eg, myoclonus or parkinsonism), without evidence of neurodegeneration. There are three clinically defined entities: dopa-responsive dystonia (DRD; DYT5), myoclonus-dystonia (M-D; DYT11), and rapid-onset dystonia-parkinsonism (RDP; DYT12), which are characterized by marked phenotypic heterogeneity.

\section{DRD or Segawa disease}

DRD or Segawa disease is mainly a pediatric-onset disorder due to defects in dopamine synthesis. The usual age of onset varies between 4 and 6 years. The ratio of females to males is $2.5: 1 .^{30}$ Prevalence has been reported to be 0.5 to 1 per million, but it is likely underestimated as the penetrance is low, and atypical cases are frequent. ${ }^{31}$ The onset is often insidious, with fatigability, clumsiness of gait, and dystonic postures often limited to one foot. ${ }^{32,33}$

In children older than 10 years, dystonia of an upper limb or postural tremor may be the first manifestations. ${ }^{34}$ Mild parkinsonian features such as rigidity of the limbs and trunk and hypomimia are commonly present. A progressive increase in severity of the dystonia during the day and a marked decrease, sometimes complete disappearance following sleep, are highly characteristic. The disorder is progressive and may lead to severe disability. The involvement of other parts of the body may occur quickly or take up to ten years. Cognitive functions are preserved.

Dystonia and/or parkinsonism usually show a rapid, marked and sustained response to low doses (3-5 mg/kg/ day) of L-dopa combined with an inhibitor of peripheral decarboxylation helping to determine the clinical diagnosis. The response is independent from the delay in initiating treatment. Autosomal dominant guanosine triphosphate cyclohydrolase (GTPCH) deficiency (DYT5) is the most frequent enzymatic defect leading to Segawa disease. Almost $75 \%$ of DRD index cases of a European large series showed this defect. ${ }^{35}$

Autosomal recessive forms of GTPCH have been reported. ${ }^{36}$ Autosomal-recessive forms of DRD (ArDRD) are also caused by homozygous or compound heterozy- gous mutations of the tyrosine hydroxylase $(\mathrm{TH})$ and the sepiapterin reductase (SPR). ${ }^{37}$ In ArDRD, the phenotype is generally more severe, including cognitive impairment and developmental delay, and it may also be called infantile encephalopathic phenotype (IEP). ${ }^{3}$ Response to L-dopa treatment in IEP differs from Segawa disease. Only in rare cases low-dose of L-dopa may produce a rapid improvement of symptoms. In most of these patients low L-dopa doses may produce marked choreic and/or dystonic movements. In most of these patients a very slow titration of the dose is necessary, and effective therapeutic levels of L-dopa cannot often be achieved. Even low doses may produce marked choreic and/or dystonic movements. Prognosis of IEP differs from Segawa disease even in cases that partially respond to dopaminergic therapy; clumsiness and mild mental retardation is often reported.

Recently, a new condition named dopamine-transporter deficiency syndrome (DTDS) has been reported in some patients with IEP caused by mutations in the dopamine transporter-encoding gene (SLC6A3). Studies of CSF neurotransmitters have shown elevated HVA/HIAA ratios. Dopamine transporter scan with single-photon emission computerized tomography (DaTSCAN SPECT) imaging shows complete loss of dopamine-transporter activity in the basal nuclei. $^{38}$

\section{Myoclonus-dystonia (M-D) (DYTII)}

The onset of the disease occurs during childhood or adolescence. The presenting symptom is usually myoclonus, involving the upper part of the body (neck, trunk, limb), with predominance of proximal muscles. Cranial muscles can also be affected, including laryngeal muscles. ${ }^{39-43}$ Dystonia is associated with myoclonus in more than half of the patients, usually causing little or no disability. Dystonia typically involves the neck or the arms (torticollis, writer's cramp). ${ }^{40,41,44-46}$ A marked improvement of motor symptoms (mainly myoclonus) following alcohol ingestion and the presence of psychiatric symptoms, such as obsessivecompulsive disorders, alcohol abuse, depression, and anxiety, is frequently reported. ${ }^{44,47-49}$ The course of the disease is usually benign but there is a wide variability of outcomes among patients, even within the same family. ${ }^{41}$

M-D is caused by heterozygous mutations of the epsilon-sarcoglycan gene ( $S G C E$ ). More than 50 different heterozygous $S G C E$ mutations have been identified. ${ }^{50}$ These mutations are thought to produce a loss-of-function and do not allow the drawing of genotype-phenotype correlations. However, marked differences in disease severity suggest an 
influence of environmental or genetic modifiers. A genetic peculiarity of $S G C E$ is maternal genomic imprinting. ${ }^{51}$

\section{Rapid-onset dystonia-parkinsonism (RDP, DYT / 2)}

The disease is characterized by dystonia and parkinsonism with abrupt onset. ${ }^{52,53}$ In its genetic form, the inheritance mode is autosomal dominant with reduced penetrance and de novo mutations have been reported. ${ }^{54,55}$ One monogenetic cause of RDP is a mutation in the gene for the alpha subunit of the $\mathrm{Na}^{+} / \mathrm{K}^{+}$-ATPase three (a3; ATP1A3). Although only a few families and sporadic cases with this disorder have been reported the clinical peculiarities make it of special interest. The disorder usually begins between 15 and 45 years of age. The hallmarks are abrupt onset of motor symptoms over a few minutes to 30 days, with a rostrocaudal involvement and prominent bulbar findings. The onset often follows physical or emotional stress resulting in permanent neurological disability. ${ }^{54}$ Most patients remain stable or demonstrate slight improvement years after the abrupt onset of symptoms. The disorder is transmitted as an autosomal dominant trait with variable expressivity and reduced penetrance. Mutations in the ATP1A3 (chromosome 19q13), a gene related with the $\mathrm{NA}^{+} / \mathrm{K}^{+}$ATPase alpha3, are the cause of the disorder. ${ }^{54,55} \mathrm{RDP}$ is the first known dystonic condition linked to a membrane ion channel abnormality. All investigations remain negative except a CSF low level of HVA, suggesting a presynaptic defect in the nigrostriatal pathways. ${ }^{56}$

Recently a novel gene PRKRA (protein kinase, interferoninducible double-stranded RNA-dependent activator) for young-onset dystonia-parkinsonism (DYT16) has been identified. ${ }^{57}$

\section{Other primary generalized dystonias}

\section{X-linked deafness dystonia}

A few families with the X-linked dystonia-deafness syndrome (also named Mohr-Tranebjaerg syndrome) have been reported. ${ }^{58,59}$ The disease is characterized by onset of sensorineural deafness usually before age of 2 years. Severe progressive generalized dystonia starts around 7 years of age. Cases of dystonia onset as late as the age of 30 years have been reported, which suggests that the clinical features have a broader spectrum than previously considered. ${ }^{60,61}$ Most of the subjects became confined to a wheelchair between the ages of 9 and 22 years. Mental retardation, visual impairment due to cortical blindness, or related to optic neuropathy, ${ }^{62}$ corticospinal tract involvement, and psychiatric manifestations (irritability, anxiety, paranoia) may be associated features. A candidate gene for this disorder, called DDP (deafness/dystonia peptide) or TIMM8A (probably encoding for Mitochondrial import inner membrane translocase subunit Tim8 A, a zinc-binding protein) has been identified on chromosome Xq22. ${ }^{63}$ The protein (DDP protein) is located in the mitochondrial intermembrane space, therefore mutated DDP protein may disrupt the mitochondrial function. ${ }^{64}$ Several mutations including intronic mutations have been reported. ${ }^{65}$ In at least one of the reported mutations, carrier females also experience dystonia but, unlike in males, it has been described as focal dystonia. ${ }^{66}$

GABAergic substances as clonazepam and gammahydroxybutyric acid have been reported to be useful. ${ }^{60}$

\section{Transient idiopathic dystonia of infancy}

Transient dystonia of infancy usually appears before 5 months of age. ${ }^{67,68}$ Affected infants present with abnormal postures usually limited to one upper or lower limb. The postures may occasionally involve the trunk, either arms, or one side of the body. ${ }^{69}$ When prone, the infant often maintains forced forearm pronation, using the back of the hand as a support. In the lower limb the feet may be held in equinovarus. The postures may be intermittent. ${ }^{70}$ The rest of the neurological examination and developments are normal. The movement disorder spontaneously disappears around the first birthday. Familial cases are known. ${ }^{67,68}$ Mild forms may be frequent, and only the most marked cases may come to medical attention. The key to the diagnosis is the observation that the dystonic posture disappears when the infant carries out purposeful movements with the affected extremity. The etiology is still unknown.

When the clinical signs are typical, no complementary studies (neuroimaging, laboratory examinations) are necessary.

\section{Primary paroxysmal syndromes}

Paroxysmal dyskinesias refer to attacks of abnormal movements and postures (dystonic, choreoathetoid, or a mixture of both) with return to normality between episodes. ${ }^{71}$

Three main categories can be recognized: paroxysmal kinesigenic dyskinesia (PKD/DYT10), paroxysmal nonkinesigenic dyskinesia (PNKD1; DYT8), and paroxysmal exercise-induced dyskinesia (PED; DYT18). ${ }^{72}$ In PKD, the duration of attacks varies from seconds to hours, and the frequency of the episodes range from one per year to hundreds per day. PKD is characterized by dystonia or choreodystonia induced by a sudden change in position, classically from sitting to the standing position. 
PNKD is characterized by spontaneous attacks at rest that tend to be more dystonic in nature, although chorea, athetosis, and ballism can occur. Episodes can last from seconds to several hours and may have long attack-free intervals. Onset is in childhood with a tendency for the attacks to diminish with age. ${ }^{73}$ Symptoms can be precipitated by alcohol or caffeine and to a lesser extent by nicotine, excitement, fatigue, hunger, and emotional stress. Paroxysmal choreoathetosis with clinical characteristics similar to those of PNKDs with associated spasticity has been described under the term of autosomal dominant paroxysmal choreoathetosis/spasticity syndrome (CSE) and linkage to chromosome $1 \mathrm{p}$ has been demonstrated.$^{74}$ In the PED, the attacks occur after 10 or 15 minutes of continuing exercise. The attacks are usually dystonic and appear most commonly in the lower limbs after prolonged walking or running. Dystonic episodes usually cease in 10-15 minutes after stopping the exercise. ${ }^{75}$

Patients with SLC2A1 gene mutations (gene encoding the Glut 1 transporter) may present with PED that may be associated with epilepsy and/or mental retardation. ${ }^{76-78}$

The list of linked gene loci causing paroxysmal dyskinesia phenotypes is growing rapidly, although the genes for most of these conditions still remain unidentified. Paroxysmal dyskinesias are inherited as an autosomal dominant trait. ${ }^{79}$ PNKD is caused by mutations in the gene PNKD1 encoding for myofibrillogenesis regulator 1 . In PKD, a disease locus has been assigned to the pericentromeric region of chromosome 16 (16p11. 2-q12. 1). ${ }^{80}$ The first causative gene of PKD has been recently identified: the proline-rich transmembrane protein $2 .^{81,82}$ The gene for PED is located in the short arm of chromosome 1 (1p31.3-p35). The gene SLC $2 A 1$ codes for glucose transporter 1 (Glut1). ${ }^{77}$ Because Glut1 delivers glucose via the blood-brain barrier, dyskinesias may result from energy deficit in the basal ganglia upon exercise.

\section{Secondary dystonias}

Dystonia is often associated with other neurological symptoms in a long list of diseases, and is then called secondary dystonias.

\section{Dystonia due to structural defect}

Dystonic cerebral palsy and delayed onset dystonia will not be discussed in this review. Hemidystonia is often due to a structural lesion. The most frequent cause of hemidystonia is acute vascular occlusion of whatever etiology especially affecting the striatum and/or the caudate. ${ }^{83}$ Hemidystonia is more frequent in children than adults. ${ }^{84}$ Hemidystonia predominates in the upper limb and is very often associated with pyramidal tract signs. The first neurological manifestation is generally an acute hemiparesis. Dystonia may appear at the time hemiparesis recovers, but frequently it becomes evident only after several months or even years. ${ }^{84}$

Response to medical treatment is often poor. The best results are obtained with benzodiazepines and anticholinergic drugs. Botulinum toxin may be useful. Surgery, mainly deep brain stimulation (DBS) in particular areas of the internal globus pallidus, seems to be the treatment of choice now. ${ }^{85}$

\section{Heredodegenerative syndromes}

Heredodegenerative syndromes constitute a large and heterogeneous group of diseases in which dystonia may occur with different degrees of severity and is associated with other abnormalities including mental retardation, seizures, ataxia, neuropathy, optic atrophy, and gaze paresis. Many of these disorders are autosomal recessive, due to a heredodegenerative or metabolic diseases, and have mainly childhood onset.

\section{Glutaric aciduria and other organic acidemias with dystonia}

Glutaric aciduria type I (GAI) also termed glutaryl-CoA dehydrogenase deficiency, is an autosomal recessive disease caused by mutations in the glutaryl-CoA dehydrogenase (GCDH) gene located on chromosome 19p13.2. ${ }^{86,87}$ The $G C D H$ is a mitochondrial enzyme that plays a key role in the catabolism of lysine, hydroxylysine, and tryptophane. The severe reduction or total absence of $G C D H$ activity causes accumulation of 3-hydroxyglutaric acid and glutaric acid in plasma, urine, and CSF, which can induce neuronal death through excitotoxicity as well as mitochondrial dysfunction. ${ }^{88}$

The frequency of GAI is estimated to be 1 in 100,000 newborns. ${ }^{89}$ Clinical manifestations generally appear between 5 and 14 months, but mild symptoms such as slight motor delay and hypotonia can be observed at earlier ages. Macrocephaly at birth or developed some time later in infancy is present in about $70 \%$ of cases..$^{90,91}$ In the majority of cases, the disease starts abruptly, with focal seizures or generalized convulsions, vomiting and obtundation or lethargy, usually following an acute infectious illness. Psychomotor regression and dystonic or choreoathetotic movements appear later on. In a few patients, the onset is insidious with slowly developing psychomotor delay, hypotonia, and dystonic postures until 16 years of age..$^{92-95}$ 
The characteristic neurological sequel is generalized dystonia. Spasticity may also be evident. Complex speech alterations with combined features of hyperkinetic dysarthria, anarthria, and apraxia are common. Comprehension of language is much better than expression, which suggests that cognition is relatively preserved.

The course of the disorder is variable. GAI is a treatable condition. Ideally, treatment should start before the onset of clinical symptoms. In such cases, a diet combined with oral supplementation of L-carnitine and an aggressive treatment during acute episodes of intercurrent illness can prevent the development of clinical signs or decrease their severity. In most cases, however, the disease continues to progress in a stepwise manner with a succession of acute encephalopathic crises precipitated by infectious diseases, immunizations, and surgery during infancy or childhood. Often, with aging, dystonia tends to evolve from mobile to fixed and to be associated with parkinsonism. ${ }^{96}$ In others, it remains stationary with severe motor and language sequelae. ${ }^{97}$ About half the patients die before the age of 4 years during intercurrent illnesses.

Its pathogenesis is not clear. Glutaric and 3-hydroxyglutaric acid concentrations are increased not only in the brain but in all tissues. 3-Hydroxyglutaric and glutaric acids share structural similarities with the main excitatory amino acid glutamate and increased levels of these acids are considered to play an important role in the pathophysiology of the disease. 3-Hydroxyglutaric acid induces excitotoxic cell damage. Furthermore, glutaric and 3-hydroxyglutaric acids indirectly modulate glutamatergic and GABAergic neurotransmission (thus resulting in low GABA levels), resulting in an imbalance of excitatory and inhibitory neurotransmission. ${ }^{88}$

\section{Lesch-Nyhan spectrum}

The Lesch-Nyhan spectrum is an X-linked disorder of purine metabolism resulting from deficiency of enzyme hypoxanthine-guanine phosphorybosyl transferase (HGPRT) located on Xq26. ${ }^{98,99}$ Prenatal diagnosis is possible.

There is a continuum spectrum of neurological manifestations depending on the degree of the enzymatic deficiency. The most severe forms are known as Lesch-Nyhan disease (LND). Partial HPRT-deficient patients present symptoms with a different intensity. In the least severe form, termed Kelley-Seegmiller syndrome, the patients have gout and no neurological involvement. ${ }^{100}$ The term 'Lesch-Nyhan variants' has been introduced to include patients with HPRTrelated gout and some degree of neurological involvement, but without the complete symptomatology of LND.
LND usually has its onset between 6 and 18 months of age, with delayed psychomotor development, hypotonia or spasticity. An early sign may be the appearance of an orange-colored crystalline material in the nappies. Abnormal movements begin with fine athetoid movements of the hands and feet. When fully developed, the movements are predominantly dystonic but may include chorea and tremor. Ocular motility is affected with saccades preceded by head movement. ${ }^{101}$ A remarkable feature is aggressive behavior ( $85 \%$ of cases) directed both to the patient him/herself and to surrounding persons. Automutilation particularly affecting the lips and fingers usually begins with tooth eruption. Dysarthria is also a frequent symptom. Epilepsy, optic atrophy, and recurrent coma have been reported. ${ }^{102,103}$ Affected children also present extraneurological symptoms such as hematuria, crystalluria, and signs of hyperuricemia such as renal stones, gouty arthritis, and tophi. Other features include vomiting, macrocytic anemia, reduced growth, and delayed bone age. Cases with survival beyond their third decade of life are now frequent.

In Lesch-Nyhan variants, the grade of dystonia is less severe and appears in the form of a dystonic gait, speech difficulties, and spasticity but with normal cognitive function and behavior (no self-mutilation).

The pathophysiology of the neurological and behavioral dysfunctions remains unclear. It is assumed that the neurological symptoms do not result from the excess production of uric acid. Postmortem studies have not shown any structural changes, but they have revealed a $60 \%-90 \%$ loss of dopamine in the basal ganglia. ${ }^{104}$ Biochemical studies of the CSF and PET have also showed a decreased level of dopamine metabolites whereas serotonin and 5-hydroxyindolacetic were increased. ${ }^{105}$

\section{Homocystinuria}

Homocystinuria is caused by different enzymatic defects. The most common is cystathionine $\beta$-synthase deficiency. A few cases of homocystinuria with slowly progressive dystonia as a tardive symptom have been reported. ${ }^{106,107} \mathrm{In}$ these cases, the age of onset of dystonia ranges from 4 to 21 years.

The cause of the movement disorder is unclear. Vascular disease is probable. In homocystinuria, arterial and venous thrombosis of the cerebral cortex and basal ganglia have been reported, but no neuroimaging evidence of lesion in basal ganglia in cases with dystonia have been described. Moreover, a postmortem case did not show pathology in the vessels of the basal ganglia. ${ }^{108,109}$ 


\section{Hartnup disease}

Hartnup disease is an inherited recessive defect in amino acid transport due to mutations in the SLC6A19 gene. ${ }^{110}$ Light-sensitive dermatitis is usually the first symptom occurring in the late infantile or juvenile ages. Recurrent episodes of ataxia are a common neurologic symptom. Dystonic features and intermittent dystonia have been reported. ${ }^{111}$ Spontaneous improvement may occur. Nicotinamide therapy may improve the neurological symptoms.

\section{Niemann-Pick disease type C (NPC)}

Niemann-Pick disease type $\mathrm{C}$ is an autosomal recessive lipid storage disorder that is characterized by impaired intracellular cholesterol homeostasis and defective cholesterol trafficking through the late endosomal/lysosomal system. ${ }^{12}$ The resulting accumulation of unesterified cholesterol, predominantly in cells of the spleen, liver, and brain, leads to a range of clinical manifestations. ${ }^{113}$ These include hepatosplenomegaly, psychiatric disorders, and neurological problems. A mutated gene (NPC1) on chromosome 18q11-12 is responsible for more than $90 \%$ of cases. ${ }^{109} \mathrm{~A}$ few cases are due to mutations in the $H E 1 / N P C 2$ gene. ${ }^{114}$

The disease features vertical supranuclear gaze palsy, especially when looking downward. Clinical manifestations at onset usually include intellectual regression, dysarthria, and gait disorder. Movement disorder can predominate and consists mainly of dystonia. Cerebellar and pyramidal signs then appear. Epilepsy occurs in about one-third of patients. Organomegaly is common (but not constant). ${ }^{115}$ Magnetic resonance imaging (MRI) of the brain shows ranges from normal to mild posterior periventricular white matter hyperintensity.

Bone marrow testing shows foamy cells or sea-blue histiocytes. NPC can be diagnosed with a culture of skin fibroblasts by demonstrating deficient esterification of lowdensity lipoprotein-derived cholesterol or by filipin staining of free intracellular cholesterol.

No specific treatment for NPC is available. Miglustat, an iminosugar that inhibits glucosylceramide synthase, may show clinical benefit. ${ }^{116}$

\section{Other neurologic disorders with dystonia \\ Infantile bilateral striatal necrosis, infantile thalamic necrosis}

Friede (1975) proposed the term 'infantile bilateral striatal necrosis' (IBSN) to designate a neuropathological syndrome featuring bilateral symmetrical spongy degeneration of both putamina and caudate nuclei and occasionally of the thalami. ${ }^{117}$ The number of cases has increased with the change from a neuropathological to a neuroimaging syndrome. The lesions can now been recognized in living patients by computed tomography (CT) scan that shows hypodense images in the involved areas ${ }^{118}$ and, better, by MRI that shows an increased T2 signal in the same zones. ${ }^{119}$

Progress in the knowledge of mitochondrial disorders and organic acidurias shows that symmetrical striatal lesions are common in these diseases and suggests that many of the cases reported as IBSN may have been due to metabolic disorders decompensated by an acute infection, eg, glutaric aciduria. ${ }^{120}$ Therefore, those cases in which no organic aciduria was identified and lactic acidosis was not documented are probably unproved mitochondrial disorders.

Typical cases of acute IBSN are characterized by an acute onset of rigidity, dystonia, chorea, ballismus, and a stereotyped response to stimuli whether pleasant or painful, with monotonous crying, grimacing and hyperextension of the neck. ${ }^{121}$ Epilepsy is rare. Some patients develop symptoms soon after a variety of infections, including respiratory tract infections, and mumps of mycoplasma pneumoniae. ${ }^{122}$ On imaging, there is often extensive edema of the white matter in addition to symmetrical hypodensities of the striatum. MRI lesions can disappear or persist over time. ${ }^{123}$ Some patients may die shortly after the acute phase, but usually a gradual improvement occurs, in some cases even after several months. Sequelae such as dystonia or hemiparesis can result. ${ }^{118,123}$

Although some familial cases are on record, most cases of IBSN are sporadic. ${ }^{124}$ The pathogenesis remains unknown, but a parainfectious mechanism is probable. Cases with acute IBSN presented shortly after streptoccal pharyngitis, with high streptocccal titers, and antibodies reactive against basal ganglia constituents have been reported, which suggests an autoimmune etiology in these cases. ${ }^{125}$

\section{Infantile thalamic necrosis}

Cases of acute necrosis of both thalami ('acute necrotizing encephalopathy of children') following an acute viral infection have been reported initially from Japan where this condition seems to predominate. ${ }^{126}$ It has also been reported in Caucasians. ${ }^{127}$ Half the cases started acutely between 6 and 18 months of age. ${ }^{126}$ Hyperthermia, coma, convulsions, and decerebrate, or decorticate postures are common in the acute stage. The course is often severe, leading to death in a quarter of the cases, or to severe residual impairment 
with quadriplegia, microcephaly, dystonia, and mental retardation, but a 'mild' form with selective reversible thalamic involvement and complete recovery exists. ${ }^{128}$ Early in the course, bilateral hyperechogenic thalamic lesions may be observed by ultrasound. CT scan or MRI will show multifocal symmetrical lesions in the thalami and usually also show lesions in the pons, mesencephalon, cerebellum, and white matter. Hyperproteinorrachia during the acute illness can be present. ${ }^{129}$ Increased serum CPK, GOT, GPT, and lactate dehydrogenase are usually present, but they seldom have hyperammonemia or hypoglycemia, which is important for differentiating diagnosis of Reye syndrome. ${ }^{126}$ Causal or associated viral infections, usually influenza $\mathrm{A}$, have been demonstrated in several cases. ${ }^{129,130}$ Prognosis is better in older children and patients with low GOT values, without brain stem lesions and normalization of the neuroimaging on follow-up. ${ }^{128}$ Effective steroid treatment has been reported. ${ }^{131}$ These cases show some similarities to those of ISBN so the term 'infantile thalamic bilateral necrosis' have been suggested. ${ }^{127}$

\section{Biotin-responsive basal ganglia disease}

Biotin-responsive basal ganglia disease is caused by thiamine transporter-2 (hTHTR2) deficiency due to mutations in the SLC19A3 gene. ${ }^{132}$ Biotine-responsive basal ganglia disease (BBGD) was first described in 1998 in 10 Arabian patients followed by new genetically confirmed cases consisting of subacute encephalopatic episodes characterized by confusion, vomiting followed by seizures, loss of speech or dysarthria, gaze palsy, dysphagia, dystonia, and generalized stiffness, which eventually led to coma and death. ${ }^{133,134}$ Administration of high doses of biotin results in partial or complete improvement within days. If untreated, the disease may result in progressive encephalopathy. Characteristic brain MRI mainly shows bilateral necrosis of the caudate nuclei and putamen, and, when present, subtle changes in thalami. Benefit with thiamine has been also reported.

\section{Alternating hemiplegia of childhood}

Alternating hemiplegia of childhood (AHC), is a disease manifested before the age of 18 months by episodes of hemiplegia affecting either side and disappearing (sometimes by only a few minutes) with sleep. Duration episodes may last from minutes to several days. Episodes of shifting or bilateral paralysis associated to strabismus or unilateral nistagmus are characteristic features. Developmental delay and epilepsy are frequent. The cause is unknown and no laboratory or neuroimaging marker is available. The disease has been considered a form of migraine, although this hypothesis is disputed.

In $\mathrm{AHC}$, tonic and dystonic episodes that are often unilateral, are present in $90 \%$ of cases and is often the first manifestation. ${ }^{130}$ The movement disorder consisting of dystonia, myoclonus, or chorea initially appears only during the episodes, but tends to become permanent. Generalized, but asymmetrical, dystonia or choreoathetosis are almost constant in the late stages. ${ }^{135,136}$ Flunarizine is partially effective in about half of patients. ${ }^{137}$

\section{Treatment options in children}

Treatment for most forms of dystonia is symptomatic and benefit may be incomplete or accompanied by intolerable side effects. These options include drugs (systemic or focal treatments, such as botulinum toxin) and surgical interventions. There are several therapies including anticholinergic medications, dopamine blocking and depleting agents, baclofen, and benzodiazepines, which have been recommended based on small uncontrolled trials. ${ }^{138}$

Among medical options, the usual first choice is highdose anticholinergic treatment. However, the absolute and comparative efficacy and tolerability of anticholinergic agents in dystonia is poorly documented in children. Therefore, no recommendations can be made to guide prescribing (good practice point). ${ }^{139}$ Moreover, children typically tolerate higher doses than adults. No controlled trials were available on the effects of this type of treatment. There is a lack of evidence on the positive effect of tetrabenazine to give recommendations for this type of treatment (good practice point). Carbidopa/levodopa is the mainstay of treatment in DRD. However, other forms of dystonia may respond partially to levodopa. Since complete response to levodopa can be diagnostic for DRD and because of its potential benefit, a trial of carbidopa/levodopa is highly recommended for all children with dystonia. ${ }^{140}$

Botulinum toxin treatment is the first choice treatment for most types of focal dystonia. In children it is less used because dystonic forms are mainly generalized, but it might also be helpful in controlling the most disabling symptoms of segmental or generalized dystonia. ${ }^{141,142}$ Botulinum toxin can be regarded as first-line treatment for primary cranial (excluding oromandibular) or cervical dystonia. Botulinum toxin is safe and efficacious when repeated treatments are performed over many years, but excessive cumulative doses may be dangerous, particularly in children. Following preliminary suggestions that intrathecal baclofen infusion could 
improve dystonia, subsequent observations have shown that this form of treatment is particularly helpful when spasticity coexists with dystonia, as in cerebral palsy. ${ }^{143-146}$

Long-term electrical stimulation of the globus pallidum internum (GPi) is now established as an effective treatment for various types of movement disorders including dystonia. The use of DBS for dystonia currently addresses in particular primary generalized or segmental forms, in patients who do not achieve sufficient relief with conservative approaches. Pallidal DBS is considered a good option, particularly for primary generalized or segmental dystonia, after medication or botulinum toxin has failed to provide adequate improvement. It has been observed that patients with DYT1 dystonia have a better outcome than the DYT1 negative, and that the earlier the intervention is performed during disease course, the better the outcome. ${ }^{147,148}$ DBS seems to be especially successful in children suffering from generalized dystonia. The age of the patient could not be shown to have a direct predictive significance for the outcome. ${ }^{148-150}$ A shorter duration of the illness - independently from its onset - enhances the effect of stimulation. These data support early intervention. In earlyonset dystonia in children, age intervention should thus not be delayed. Preliminary information on a small number of patients with M-D treated with pallidal DBS indicates that both myoclonic features and dystonia can improve. ${ }^{151}$

In a review of 109 patients with heredodegenerative and secondary syndromes treated with GPi-DBS implants, some cases with favorable outcomes were reported in nearly all groups. ${ }^{152}$ Furthermore, eight of 13 patients with PKAN had striking motor improvement. ${ }^{153}$

\section{Conclusion}

Dystonia syndromes are among the most commonly observed movement disorders in clinical practice both in adults and children. The dystonia syndromes represent a complex, clinically and genetically heterogeneous set of movement disorders. In primary dystonias, dystonia is the only neurological symptom except for tremor and functional disorders of the neurons with no apparent neuronal loss with a strong genetic component that appears to cause the disease. It is most likely that many of the yet unknown genes associated to primary dystonia still have to be identified. Dystonia may be associated with other neurological symptoms in a long list of diseases, due to structural, metabolic, and heredodegenerative processes. Treatment for most forms of dystonia is symptomatic and benefit may be incomplete or accompanied by intolerable side effects. These options include drugs (systemic or focal treatments, such as botulinum toxin) and surgical interventions. Research is focusing on identification of pathogenic treatments for the most common genetic forms of dystonia.

\section{Disclosure}

The authors report no conflicts of interest in this work.

\section{References}

1. Albanese A. The clinical expression of primary dystonia. $J$ Neurol. 2003;250(10):1145-1151.

2. Albanese A, Jankovic J, editors. Hyperkinetic Movement Disorders. Differential diagnosis and treatment. London, UK: Wiley-Blackwell; 2011.

3. Fernandez-Alvarez E. Dystonia. The paediatric perspective. Eur J Neurol. 2010;17(Suppl 1):46-51.

4. Schneider SA. Secondary dystonia: clinical clues and syndromic associations. In: Albanese A, Jankovic J, editors. Hyperkinetic Movement Disorders. Differential diagnosis and treatment. London, UK: Wiley-Blackwell; 2011:212-226.

5. Fernandez-Alvarez E. Prevalence of paediatric movement disorders. In: Fernandez-Alvarez E, Tolosa E, Arzimanogolou A, editors. Pediatric Movement Disorders. Montrouge, France: John Libbey Eurotext; 2005:1-18.

6. Wenning GK, Kiechl S, Seppi K, et al. Prevalence of movement disorders in men and women aged 50-89 years (Bruneck study cohort): A population-based study. Lancet Neurol. 2005;4(12):815-820.

7. Defazio G. The epidemiology of primary dystonia: Current evidence and perspectives. Eur J Neurol. 2010;17(Suppl 1):9-14.

8. Valente EM, Albanese A. Advances in the genetics of primary torsion dystonia. F1000 Biol Rep. 2010;2:41.

9. Bressman SB, de Leon D, Kramer PL, et al. Dystonia in Ashkenazi Jews: Clinical characterization of a founder mutation. Ann Neurol. 1994;36(5):771-777.

10. Valente EM, Warner TT, Jarman PR, et al. The role of DYT1 in primary torsion dystonia in Europe. Brain. 1998;121(Pt 12):2335-2339.

11. Zorzi G, Garavaglia B, Invernizzi F, et al. Frequency of DYT1 mutation in early onset primary dystonia in Italian patients. Mov Disord. 2002;17(2):407-408.

12. Risch N, de Leon D, Ozelius L, et al. Genetic analysis of idiopathic torsion dystonia in ashkenazi jews and their recent descent from a small founder population. Nat Genet. 1995;9(2):152-159.

13. Frederic M, Lucarz E, Monino C, et al. First determination of the incidence of the unique TOR1A gene mutation, c.907delGAG, in a mediterranean population. Mov Disord. 2007;22(6):884-888.

14. Bressman SB, Sabatti C, Raymond D, et al. The DYT1 phenotype and guidelines for diagnostic testing. Neurology. 2000;54(9):1746-1752.

15. Gatto EM, Pardal MM, Micheli FE. Unusual phenotypic expression of the DYT1 mutation. Parkinsonism Relat Disord. 2003;9(5):277-279.

16. Opal P, Tintner R, Jankovic J, et al. Intrafamilial phenotypic variability of the DYT1 dystonia: From asymptomatic TOR1A gene carrier status to dystonic storm. Mov Disord. 2002;17(2):339-345.

17. Hanson PI, Whiteheart SW. AAA+ proteins: Have engine, will work. Nat Rev Mol Cell Biol. 2005;6(7):519-529.

18. Goodchild RE, Dauer WT. Mislocalization to the nuclear envelope: An effect of the dystonia-causing torsinA mutation. Proc Natl Acad Sci US A. 2004;101(3):847-852.

19. Hewett JW, Zeng J, Niland BP, Bragg DC, Breakefield XO. Dystoniacausing mutant torsin A inhibits cell adhesion and neurite extension through interference with cytoskeletal dynamics. Neurobiol Dis. 2006;22(1):98-111.

20. Giles LM, Chen J, Li L, Chin LS. Dystonia-associated mutations cause premature degradation of torsinA protein and cell-typespecific mislocalization to the nuclear envelope. Hum Mol Genet. 2008;17(17):2712-2722. 
21. Granata A, Koo SJ, Haucke V, Schiavo G, Warner TT. CSN complex controls the stability of selected synaptic proteins via a torsinA-dependent process. EMBO J. 2011;30(1):181-193.

22. Almasy L, Bressman SB, Raymond D, et al. Idiopathic torsion dystonia linked to chromosome 8 in two Mennonite families. Ann Neurol. 1997;42(4):670-673

23. Blanchard A, Ea V, Roubertie A, et al. DYT6 dystonia: review of the literature and creation of the UMD Locus-Specific Database (LSDB) for mutations in the THAP1 gene. Hum Mutat. 2011;32(11): 1213-1224.

24. Fuchs T, Gavarini S, Saunders-Pullman R, et al. Mutations in the THAP1 gene are responsible for DYT6 primary torsion dystonia. Nat Genet. 2009;41(3):286-288.

25. Gavarini S, Cayrol C, Fuchs T, et al. Direct interaction between causative genes of DYT1 and DYT6 primary dystonia. Ann Neurol. 2010;68(4):549-553

26. Mazars R, Gonzalez-de-Peredo A, Cayrol C, et al. The THAP-zinc finger protein THAP1 associates with coactivator HCF-1 and O-GlcNAc transferase: A link between DYT6 and DYT3 dystonias. J Biol Chem 2010;285(18):13364-13371.

27. Bentivoglio AR, Ialongo T, Contarino MF, Valente EM, Albanese A. Phenotypic characterization of DYT13 primary torsion dystonia. Mov Disord. 2004;19(2):200-206.

28. Gimenez-Roldan S, Delgado G, Marin M, Villanueva JA, Mateo D Hereditary torsion dystonia in gypsies. Adv Neurol. 1988;50:73-81.

29. Chouery E, Kfoury J, Delague V, et al. A novel locus for autosomal recessive primary torsion dystonia (DYT17) maps to 20p11.22-q13.12. Neurogenetics. 2008;9(4):287-293.

30. Nygaard TG, Marsden CD, Duvoisin RC. Dopa-responsive dystonia Adv Neurol. 1988;50:377-384.

31. Nygaard TG, Snow BJ, Fahn S, Calne DB. Dopa-responsive dystonia: clinical characteristics and definition. In: Segawa M, editor. Hereditary Responsive Dystonia with Marked Diurnal Fluctuation. New York, NY: The Partenon Publ Group Lanc; 1993:21-35.

32. Rondot P, Aicardi J, Goutieres F, Ziegler M. Dopa-sensitive dystonia Rev Neurol (Paris). 1992;148(11):680-686.

33. Nygaard TG. Dopa-responsive dystonia. delineation of the clinical syndrome and clues to pathogenesis. Adv Neurol. 1993;60:577-585.

34. de Yebenes JG, Moskowitz C, Fahn S, Saint Hilaire MH. Long-term treatment with levodopa in a family with autosomal dominant torsion dystonia. Adv Neurol. 1988;50:101-111.

35. Clot F, Grabli D, Cazeneuve C, et al. Exhaustive analysis of BH4 and dopamine biosynthesis genes in patients with dopa-responsive dystonia. Brain. 2009;132:1753-1763

36. Garavaglia B, Invernizzi F, Carbone ML, et al. GTP-cyclohydrolase I gene mutations in patients with autosomal dominant and recessive GTP-CH1 deficiency: Identification and functional characterization of four novel mutations. J Inherit Metab Dis. 2004;27(4):455-463.

37. Asmus F, Gasser T. Dystonia-plus syndromes. Eur J Neurol. 2010; 17 Suppl 1:37-45.

38. Kurian MA, Li Y, Zhen J, et al. Clinical and molecular characterisation of hereditary dopamine transporter deficiency syndrome: An observational cohort and experimental study. Lancet Neurol. 2011;10(1):54-62.

39. Tezenas du Montcel S, Clot F, Vidailhet M, et al. Epsilon sarcoglycan mutations and phenotype in French patients with myoclonic syndromes. J Med Genet. 2006;43(5):394-400.

40. Koukouni V, Valente EM, Cordivari C, Bhatia KP, Quinn NP. Unusual familial presentation of epsilon-sarcoglycan gene mutation with falls and writer's cramp. Mov Disord. 2008;23(13):1913-1915.

41. Nardocci N, Zorzi G, Barzaghi C, et al. Myoclonus-dystonia syndrome: Clinical presentation, disease course, and genetic features in 11 families. Mov Disord. 2008;23(1):28-34.

42. Raymond D, Saunders-Pullman R, de Carvalho Aguiar P, et al Phenotypic spectrum and sex effects in eleven myoclonusdystonia families with epsilon-sarcoglycan mutations. Mov Disord. 2008;23(4):588-592.
43. Roze E, Betuing S, Deyts C, Vidailhet M, Caboche J. Pathophysiology of Huntington's disease: An update. Rev Neurol (Paris). 2008;164(12): 977-994.

44. Asmus F, Zimprich A, Tezenas Du Montcel S, et al. Myoclonus-dystonia syndrome: Epsilon-sarcoglycan mutations and phenotype. Ann Neurol. 2002;52(4):489-492.

45. Doheny D, Danisi F, Smith C, et al. Clinical findings of a myoclonus-dystonia family with two distinct mutations. Neurology. 2002;59(8):1244-1246.

46. Valente EM, Edwards MJ, Mir P, et al. The epsilon-sarcoglycan gene in myoclonic syndromes. Neurology. 2005;64(4):737-739.

47. Marechal L, Raux G, Dumanchin C, et al. Severe myoclonus-dystonia syndrome associated with a novel epsilon-sarcoglycan gene truncating mutation. Am J Med Genet B Neuropsychiatr Genet. 2003;119B(1) 114-117.

48. Misbahuddin A, Placzek M, Lennox G, Taanman JW, Warner TT. Myoclonus-dystonia syndrome with severe depression is caused by an exon-skipping mutation in the epsilon-sarcoglycan gene. Mov Disord. 2007;22(8):1173-1175.

49. Gerrits MC, Foncke EM, de Haan R, et al. Phenotype-genotype correlation in Dutch patients with myoclonus-dystonia. Neurology. 2006;66(5):759-761.

50. Kinugawa K, Vidailhet M, Clot F, Apartis E, Grabli D, Roze E. Myoclonus-dystonia: An update. Mov Disord. 2009;24(4):479-489.

51. Grabowski M, Zimprich A, Lorenz-Depiereux B, et al. The epsilonsarcoglycan gene (SGCE), mutated in myoclonus-dystonia syndrome, is maternally imprinted. Eur J Hum Genet. 2003;11(2):138-144.

52. Dobyns WB, Ozelius LJ, Kramer PL, et al. Rapid-onset dystoniaparkinsonism. Neurology. 1993;43(12):2596-2602.

53. Brashear A, Dobyns WB, de Carvalho Aguiar P, et al. The phenotypic spectrum of rapid-onset dystonia-parkinsonism (RDP) and mutations in the ATP1A3 gene. Brain. 2007;130(Pt 3):828-835.

54. de Carvalho Aguiar P, Sweadner KJ, Penniston JT, et al. Mutations in the $\mathrm{Na}^{+} / \mathrm{K}^{+}$-ATPase alpha3 gene ATP1A3 are associated with rapid-onset dystonia parkinsonism. Neuron. 2004;43(2):169-175.

55. Post B, Ozelius LJ, Tijssen MAJ. Juvenile rapid-onset dystonia parkinsonism due to a 'de novo' mutation in the ATP1A3 gene. J Pediatr Neurol. 2009;7(2):171-173.

56. Brashear A, Butler IJ, Hyland K, Farlow MR, Dobyns WB. Cerebrospinal fluid homovanillic acid levels in rapid-onset dystoniaparkinsonism. Ann Neurol. 1998;43(4):521-526.

57. Camargos S, Scholz S, Simon-Sanchez J, et al. DYT16, a novel youngonset dystonia-parkinsonism disorder: Identification of a segregating mutation in the stress-response protein PRKRA. Lancet Neurol. 2008;7(3):207-215.

58. Mohr J, Mageroy K. Sex-linked deafness of a possibly new type. Acta Genet Stat Med. 1960;10:54-62.

59. Tranebjaerg L, Schwartz C, Eriksen H, et al. A new X linked recessive deafness syndrome with blindness, dystonia, fractures and mental deficiency is linked to Xq22. J Med Genet .1995;32:257-263.

60. Kreisel SH, Binder J, Wöhrle JC, et al. Dystonia in the MohrTranegjaerg syndrome responds to GABAergic substances. Mov Disord. 2004;19:1241-1243

61. Ujike H, Tanabe Y, Takehisa Y, Hayabara T, Kuroda S. A family with $\mathrm{X}$-linked dystonia-deafness syndrome with a novel mutation in the DDP gene. Arch Neurol. 2001;58:1004-1007.

62. Aguirre LA, Pérez-Bas M, Villamar M, et al. A Spanish sporadic case of deafness-dystonia (Mohr-Tranebjaerg) syndrome with a novel mutation in the gene encoding TIMM8a, a component of the mitochondrial protein translocase complexes. Neuromuscul Disord. 2008;18(12):979-981.

63. Jin H, May M, Tranebjaerg L, et al. A novel X-linked gene, DDP, shows mutations in families with deafness (DFN-1), dystonia, mental deficiency and blindness. Nat Genet. 1996;14:177-189.

64. Koehler CM, Leuenberger D, Merchant S, et al. Human deafness dystonia syndrome is a mitochondrial disease. Proc Natl Acad Sci USA. 1999;96:2141-2146. 
65. Ezquerra M, Campdelacreu J, Muñoz E, Tolosa E, Martí MJ. A novel intronic mutation in the DDP1 gene in a family with X-linked dystoniadeafness syndrome. Arch Neurol. 2005;62:306-308.

66. Swerdlow RH, Wooten GF. A novel deafness/dystonia peptide gene mutation that causes dystonia in female carriers of Mohr-Tranebjaerg syndrome Ann Neurol. 2001;50:537-540.

67. Willemse J. Benign idiopathic dystonia in the first year of life. Dev Med Child Neurol. 1986;28:355-363.

68. Fernández-Alvarez E. Transient movement disorders in children. J Neurol. 1998;245:1-5.

69. Deonna T, Ziegler AL, Nielsen J. Transient idiopathic dystonia in infancy. Neuropediatrics. 1991;22:220-224.

70. Angelini L, Rumi V, Lamperti E, Nardocci N Transient paroxysmal dystonia in infancy. Neuropediatrics. 1988;19:171-174.

71. Zorzi G, Conti C, Erba A, Granata T, Angelini L, Nardocci N. Paroxysmal dyskinesias in childhood. Pediatr Neurol. 2003;28(3):168-172.

72. Demirkiran M, Jankovic J. Paroxysmal dyskinesias: Clinical features and classification. Ann Neurol. 1995;38(4):571-579.

73. Bressman SB, Fahn S, Burke RE. Paroxysmal non-kinesigenic dystonia. Adv Neurol. 1988;50:403-413.

74. Auburger G, Ratzlaff T, Lunkes A, et al. A gene for autosomal dominant paroxysmal choreoathetosis/spasticity (CSE) maps to the vicinity of a potassium channel gene cluster on chromosome 1p, probably within 2 cM between D1S443 and D1S197. Genomics. 1996;31(1):90-94.

75. Bhatia KP, Soland VL, Bhatt MH, Quinn NP, Marsden CD. Paroxysmal exercise-induced dystonia: Eight new sporadic cases and a review of the literature. Mov Disord. 1997;12(6):1007-1012.

76. Suls A, Dedeken P, Goffin K, et al. Paroxysmal exercise-induced dyskinesia and epilepsy is due to mutations in SLC2A1, encoding the glucose transporter GLUT1. Brain. 2008;131:1831-1844.

77. Weber YG, Storch A, Wuttke TV, et al. GLUT1 mutations are a cause of paroxysmal exertion-induced dyskinesias and induce hemolytic anemia by a cation leak. J Clin Invest. 2008;118(6):2157-2168.

78. Zorzi G, Castellotti B, Zibordi F, Gellera C, Nardocci N. Paroxysmal movement disorders in GLUT1 deficiency syndrome. Neurology. 2008;71(2):146-148.

79. Fink JK, Hedera P, Mathay JG, Albin RL. Paroxysmal dystonic choreoathetosis linked to chromosome 2q: Clinical analysis and proposed pathophysiology. Neurology. 1997;49(1):177-183.

80. Bennett LB, Roach ES, Bowcock AM. A locus for paroxysmal kinesigenic dyskinesia maps to human chromosome 16. Neurology. 2000;54(1):125-130.

81. Wang JL, Cao L, Li XH, et al. Identification of PRRT2 as the causative gene of paroxysmal kinesigenic dyskinesias. Brain. 2011;134:3490-3498.

82. Lee HY, Huang Y, Bruneau N, et al. Mutations in the gene PRRT2 cause paroxysmal kinesigenic dyskinesia with infantile convulsions. Cell Rep. 2012;1:2-12.

83. Nardocci N, Zorzi G, Grisoli M, et al. Acquired hemidystonia in childhood: a clinical and neuroradiologic study of 13 patients. Pediatr Neurol. 1996;15:108-113.

84. Chuang C, Fahn S, Frucht SJ. The natural history and treatment of acquired hemidystonia: report of 33 cases and review of the literature. J Neurol Neurosurg Psychiatry. 2002;72:59-67.

85. Marks WA, Honeycutt J, Acosta F, Reed M. Deep brain stimulation for pediatric movement disorders. Semin Pediatr Neurol. 2009;16:90-98.

86. Goodman SI, Markey SP, Moe PG, Miles BS, Teng CC. Glutaric aciduria; a "new" disorder of amino acid metabolism. Biochem Med. $1975 ; 12: 12-21$

87. Biery BJ, Stein DE, Morton DH, Goodman SI. Gene structure and mutations of Glutaryl-Coenzyme A dehydrogenase: impaired association of enzyme subunits that is due to an A421V substitution causes glutaric acidemia type I in the Amish. Am J Hum Genet. 1996;59:1006-1011.

88. Kolker S, Koeller DM, Okun JG, Hoffmann GF. Pathomechanisms of neurodegeneration in glutaryl-CoA dehydrogenase deficiency. Ann Neurol. 2004;55:7-12.
89. Lindner M, Kolker S, Schulze A, Christensen E, Greenberg CR, Hoffmann GF. Neonatal screening for glutaryl-CoA dehydrogenase deficiency. J Inherit Metab Dis. 2004;27:851-859.

90. Iafolla AK, Kahler SG. Megaloencephaly in the neonatal period as the initial manifestation of glutaric aciduria type I. J Pediatr. 1989;114:1004-1006

91. Hoffmann GF, Athanassopoulos S, Burlina AB, et al. Clinical course, early diagnosis, treatment, and prevention of disease in glutaryl-CoA dehydrogenase deficiency. Neuropediatrics. 1996;27:115-123.

92. Busquets C, Merinero B, Christensen E, et al. Glutaryl-CoA dehydrogenase deficiency in Spain: Evidence of two groups of patients, genetically, and biochemically distinct. Pediatr Res. 2000;48: 315-322.

93. Fernández-Álvarez E, García-Cazorla A, Sans A, et al. Hand tremor and orofacial dyskinesia: clinical manifestations of glutaric aciduria type I in a young girl. Mov Disord. 2003;18:1076-1079.

94. Bahr O, Mader I, Zschocke J, Dichgans J, Schulz JB. Adult onset glutaric aciduria type I presenting with leukoencephalopathy. Neurology. 2002;59:1802-1804.

95. Kulkens S, Harting I, Sauer S, et al. Late-onset neurologic disease in glutaryl-CoA dehydrogenase deficiency. Neurology. 2005;64:2142-2144.

96. Gitiuax C, Roze E, Kinugawa K, et al. Spectrum of movement disorders associated with glutaric aciduria type I. A study of 16 patients. Mov Disord. 2008;23:2392-2397.

97. Hoffmann GF, Athanassopoulos S, Burlina AB, et al. Clinical course, early diagnosis, treatment, and prevention of disease in glutaryl-CoA dehydrogenase deficiency. Neuropediatrics. 1996;27:115-123.

98. Lesch M, Nyhan WL. A familial disorder of uric acid metabolism and central nervous system function. Am J Med. 1964;36:561-570.

99. Jinnah HA, De Gregorio L, Harris JC, et al. The spectrum of inherited mutations causing HPRT deficiency: 75 new cases and a review of 196 previously reported cases. Mutat Res. 2000;463:309-326.

100. Kelley WN, Rosenbloom FM, Henderson JF, Seegmiller JE. A specific enzyme defect in gout associated with overproduction of uric acid. Proc Natl Acad Sci U S A. 1967;67:1735-1739.

101. Jinnah HA, Lewis RF, Visser JE, et al. Ocular motor dysfunction in Lesch-Nyhan disease. Pediatr Neurol. 2001;24:200-204.

102. Mizuno T. Long-term follow-up of ten patients with Lesch-Nyhan syndrome. Neuropediatrics. 1986;17:158-161.

103. Lynch BJ, Noetzel MJ. Recurrent coma and Lesch-Nyhan syndrome. Pediatr Neurol. 1991;7:389-391.

104. Saito Y, Takashima S. Neurotransmitter changes in the pathophysiology of Lesch-Nyhan syndrome. Brain Dev. 2000;22:S122-S131.

105. Wong DF, Harris JC, Naidu S, et al. Dopamine transporters are markedly reduced in Lesch-Nyhan disease in vivo. Proc Natl Acad Sci US A. 1996;93:5539-5543.

106. Berardelli A, Thompson PD, Zaccagnini A, et al. Two sisters with generalized dystonia associated with homocystinuria. Mov Disord. 1991;6:163-165

107. Burlina AP, Edini C, Burlina AB. Treatment of extrapyramidal symptoms in a patient with homozigous homocystinuria. J Inherit Metab Dis. 2002;25:135-136.

108. Gibson JB, Carson NAJ, Neill DW. Pathological findings in homocystinuria. J Clin Pathol. 1964;17:427-437.

109. Kemspter PAK, Brenton DP, Gale ANM, Stern GM. Dystonia in homocystinuria. J Neurol Neurosurg Psychiatry. 1988;51:859-862.

110. Seow HF, Broer S, Broer A, et al. Hartnup disorder is caused by mutations in the gene encoding the neutral aminoacid transporter SLC6A19. Nat Genet. 2004;36:1003-1007.

111. Darras BT, Ampola MG, Dietz WH, Gilmore HE. Intermittent dystonia in Hatnup disease. Pediatr Neurol. 1989;5:118-120.

112. Sturley SL, Patterson MC, Balch W, Liscum L. The pathophysiology and mechanisms of NP-C disease. Biochim Biophys Acta. 2004;1685: 83-87.

113. Vanier MT, Millat G. Niemann-Pick disease type C. Clin Genet. 2003;64:269-281. 
114. Chikh K, Vey S, Simonot C, Vanier MT, Millat G. Niemann-Pick type C disease: importance of $\mathrm{N}$-glycosylation sites for function and cellular location of the NPC2 protein. Mol Genet Metab. 2004;83:220-230.

115. Uc EY, Wenger DA, Jankovic J. Niemann-Pick disease type C: two cases and an update. Mov Disord. 2000;15:1199-1203.

116. Patterson MC, Vecchio D, Prady H, et al. Miglustat for treatment of Niemann-Pick C disease: a randomised control study. Lancet Neurol 2007;6:765-772.

117. Friede RL. Infantile bilateral striatal necrosis In: Goodman SI, Norenberg MD, Shikes RH, et al, editors. Developmental Neuropathology. Wien, Austria: Springer; 1975:88-89.

118. Goutières F, Aicardi J. Acute neurological dysfunction associated with destructive lesions of the basal ganglia in children. Ann Neurol. 1982;12:328-332.

119. Leuzzi V, Favatà I, Seri S. Bilateral striatal lesions. Dev Med Child Neurol. 1988;30(2):252-257.

120. Campistol J, Cusi V, Vernet A, Fernandez-Alvarez E. Dystonia as a presenting sign of subacute necrotizing encephalomyelopathy in infancy. Eur J Pediatr. 1986;144:589-591.

121. Yamamoto K, Chiba H, Ishitobi M, Nakagawa H, Ogawa T, Ishii K. Acute encephalopathy with bilateral striatal necrosis: favourable response to corticosteroid therapy. Eur J Paediatr Neurol. 1997;1:41-45.

122. Brandel J-P, Vidailhet M, Noseda G, Harpey J-P, Agid Y. Mycoplasma pneurmoniae postinfectious encephalomyelitis with bilateral striatal necrosis. Mov Disord. 1996;11:333-335.

123. Fujita K, Takeuchi Y, Nishimura A, Takada H, Sawada T. Serial MRI in infantile bilateral striatal necrosis. Pediatr Neurol. 1994; 10:157-160.

124. Craver RD, Duncan MC, Nelson JS. Familial dystonia and choreoathetosis in three generations associated with bilateral striatal necrosis. J Child Neurol. 1996;11:185-188.

125. Dale RC, Church AJ, Benton S, et al. Post-streptococcal autoimmune dystonia with isolated bilateral striatal necrosis. Dev Med Child Neurol. 2002;44:485-489.

126. MizuguchI M. Acute necrotizing encephalopathy of childhood: a novel form of acute encephalopathy prevalent in Japan and Taiwan. Brain Dev. 1997;19:81-92.

127. Campistol J, Gassio R, Pineda M, Fernandez-Alvarez E. Acute necrotizing encephalopathy of childhood (infantile thalamic necrosis): two non-Japanese cases. Dev Med Child Neurol. 1998;40:771-774.

128. Yoshikawa H, Watanabe T, Abe T, Oda Y. Clinical diversity in acute necrotizing encephalopathy. J Child Neurol. 1999;14:249-255.

129. Fujimoto Y, Shibata M, Tsuyuki M, Okada M, Tsuzuki K. Influenza A virus encephalopathy with symmetrical thalamic lesions. Eur J Pediatr. 2000;159:319-321.

130. Voudris KA, Skaardoutsou A, Haronitis J, Vagiakou EA, Zeis PM. Brain MRI findings in influenza A-associated acute necrotizing encephalopathy of childhood. Eur J Paediatr Neurol. 2001;5:199-202.

131. Ravid S, Topper L, Eviatar L. Acute necrotizing encephalopahy presenting as a basal ganglia syndrome. J Child Neurol. 2001;16:461-462.

132. Zeng WQ, Al-Yamani E, Acierno JS Jr, et al. Biotin-responsive basal ganglia disease maps to $2 \mathrm{q} 36.3$ and is due to mutations in SLC19A3. Am J Hum Genet. 2005;77:16-26.

133. Ozand PT, Gascon GG, Al Essa M, et al. Biotin-responsive basal ganglia disease: a novel entity. Brain. 1998;121:1267-1279.
134. Debs R, Depienne C, Rastetter A, et al. Biotin-responsive basal ganglia disease in ethnic Europeans with novel SLC19A3 mutations. Arch Neurol. 2010;67:126-130.

135. Aicardi J. Aicardi-Goutières syndrome: special type early-onset encephalopathy. Eur J Paediatr Neurol. 2002;6(Suppl A):A1-A7.

136. Mikati MA, Kramer U, Zupanc ML, Shanahan RJ. Alternating hemiplegia of childhood: clinical manifestations and long-term outcome. Pediatr Neurol. 2000;23:134-141.

137. Casaer P. Flunarizine in alternating hemiplegia in childhood. An international study of 12 children. Neuropediatrics. 1987;18:191-195.

138. Kartha N. Therapeutic challenges in dystonia. Neurol Clin. 2010;28(4):927-940.

139. Balash Y, Giladi N. Efficacy of pharmacological treatment of dystonia: Evidence-based review including meta-analysis of the effect of botulinum toxin and other cure options. Eur J Neurol. 2004; 11(6):361-370

140. Albanese A, Asmus F, Bhatia KP, et al. EFNS guidelines on diagnosis and treatment of primary dystonias. Eur J Neurol. 2011;18(1):5-18.

141. Burlina AP, Zara G, Hoffmann GF, Zschocke J, Burlina AB. Management of movement disorders in glutaryl-CoA dehydrogenase deficiency: Anticholinergic drugs and botulinum toxin as additional therapeutic options. J Inherit Metab Dis. 2004;27(6):911-915.

142. Sanger TD, Kukke SN, Sherman-Levine S. Botulinum toxin type B improves the speed of reaching in children with cerebral palsy and arm dystonia: An open-label, dose-escalation pilot study. J Child Neurol. 2007;22(1):116-122.

143. Narayan RK, Loubser PG, Jankovic J, Donovan WH, Bontke CF. Intrathecal baclofen for intractable axial dystonia. Neurology. 1991;41(7):1141-1142.

144. Albright AL, Ferson SS. Intrathecal baclofen therapy in children. Neurosurg Focus. 2006;21(2):e3.

145. Bardutzky J, Tronnier V, Schwab S, Meinck HM. Intrathecal baclofen for stiff-person syndrome: Life-threatening intermittent catheter leakage. Neurology. 2003;60(12):1976-1978.

146. Hou JG, Ondo W, Jankovic J. Intrathecal baclofen for dystonia. Mov Disord. 2001;16(6):1201-1202.

147. Alterman RL, Snyder BJ. Deep brain stimulation for torsion dystonia. Acta Neurochir Suppl. 2007;97(Pt 2):191-199.

148. Isaias IU, Alterman RL, Tagliati M. Outcome predictors of pallidal stimulation in patients with primary dystonia: The role of disease duration. Brain. 2008;131:1895-1902.

149. Coubes P, Roubertie A, Vayssiere N, Hemm S, Echenne B. Treatment of DYT1-generalised dystonia by stimulation of the internal globus pallidus. Lancet. 2000;355(9222):2220-2221.

150. Zorzi G, Marras C, Nardocci N, et al. Stimulation of the globus pallidus internus for childhood-onset dystonia. Mov Disord. 2005;20(9):1194-1200.

151. Gruber D, Kuhn AA, Schoenecker T, et al. Pallidal and thalamic deep brain stimulation in myoclonus-dystonia. Mov Disord. 2010;25(11):1733-1743.

152. Speelman JD, Contarino MF, Schuurman PR, Tijssen MA, de Bie RM Deep brain stimulation for dystonia: Patient selection and outcomes. Eur J Neurol. 2010;17(Suppl 1):102-106.

153. Timmermann L, Pauls KA, Wieland K, et al. Dystonia in neurodegeneration with brain iron accumulation: Outcome of bilateral pallidal stimulation. Brain. 2010;133:701-712

\section{Dovepress}

\section{Publish your work in this journal}

Degenerative Neurological and Neuromuscular Disease is an international, peer-reviewed, open access journal focusing on research into degenerative neurological and neuromuscular disease, identification of therapeutic targets and the optimal use of preventative and integrated treatment interventions to achieve improved outcomes, enhanced survival and quality of life for the patient. The manuscript management system is completely online and includes a very quick and fair peer-review system. Visit http://www.dovepress.com/testimonials.php to read real quotes from published authors. 